\title{
Invertebrate Taxonomy
}

National Cancer Institute

\section{Source}

National Cancer Institute. Invertebrate Taxonomy. NCI Thesaurus. Code C19056.

The systematic classification of invertebrates. 